\title{
New methods for the management of esophageal varices
}

\author{
Hiroshi Yoshida, Yasuhiro Mamada, Nobuhiko Taniai, Takashi Tajiri
}

Hiroshi Yoshida, Yasuhiro Mamada, Nobuhiko Taniai, Takashi Tajiri, Department of Surgery, Nippon Medical School, Tokyo 1138603, Japan

Correspondence to: Hiroshi Yoshida, MD, Department of Surgery, Nippon Medical School, 1-1-5 Sendagi, Bunkyo-ku, Tokyo 1138603, Japan. hiroshiy@nms.ac.jp

Telephone: +81-3-58146239 Fax: +81-3-56850989

Received: 2007-03-12 Accepted: 2007-03-23

\begin{abstract}
Bleeding from esophageal varices (EVs) is a catastrophic complication of chronic liver disease. Many years ago, surgical procedures such as esophageal transection or distal splenorenal shunting were the only treatments for EVs. In the 1970s, interventional radiology procedures such as transportal obliteration, left gastric artery embolization, and partial splenic artery embolization were introduced, improving the survival of patients with bleeding EVs. In the 1980s, endoscopic treatment, endoscopic injection sclerotherapy (EIS), and endoscopic variceal ligation (EVL), further contributed to improved survival. We combined IVR with endoscopic treatment or EIS with EVL. Most patients with EVs treated endoscopically required followup treatment for recurrent varices. Proper management of recurrent EVs can significantly improve patients' quality of life. Recently, we have performed EVL at 2-mo (bimonthly) intervals for the management of EVs. Longer intervals between treatment sessions resulted in a higher rate of total eradication and lower rates of recurrence and additional treatment.
\end{abstract}

(C) 2007 The WJG Press. All rights reserved.

Key words: Esophageal varices; Surgery; Interventional radiology; Embolization; Endoscopic treatment; Bi-monthly

Yoshida H, Mamada Y, Taniai N, Tajiri T. New methods for the management of esophageal varices. World J Gastroenterol 2007; 13(11): 1641-1645

http://www.wjgnet.com/1007-9327/13/1641.asp

\section{INTRODUCTION}

Bleeding from esophageal varices $(\mathrm{EVs})$ or gastric varices $(\mathrm{GVs})$ is a catastrophic complication of chronic liver disease. There are various treatments for EVs. Many years ago, operation was the only treatment option available. In the 1970s, techniques for interventional radiology were developed, improving the survival of patients with bleeding EVs. In the 1980s, endoscopic treatment further contributed to improved survival. In this paper, we review the evolution of treatments for EVs.

\section{DIAGNOSIS OF ESOPHAGEAL VARICES}

The Esophagogastric Varices Grading System of the Japan Society for Portal Hypertension ${ }^{[1]}$ evaluates EVs on the basis of color [white $(\mathrm{Cw})$ or blue $(\mathrm{Cb})]$, form [small and straight (F1), nodular (F2), or large or coiled (F3)], and red color signs (RCO-3).

\section{Pathomorphology of esophageal varices}

Bleeding from an EV most commonly occurs in the critical area $3 \mathrm{~cm}$ proximal to the esophagocardiac junction. Fine longitudinal veins in the lamina propria originate at the esophagocardiac junction and transverse the lamina propria toward this critical area. EVs consist of multiple dilated veins. Veins that rupture are usually located in the lamina propria $^{[2]}$. The mucosal layer covering an $\mathrm{EV}$ is somewhat thinner than that covering a GV. The lamina muscularis mucosa of the esophagus is loose, and venous pressure in the submucosa is transmitted through communicating branches to veins in the lamina propria. In contrast, the lamina muscularis mucosa of the gastric mucosa is tough and tightly integrated with the lamina propria $a^{[3]}$.

Red color signs are elevated red areas that are important for predicting the risk of variceal bleeding. Histologically, red color signs are associated with a thinning epithelial layer.

\section{Incidence and risk factors for bleeding from esophageal} varices

The incidence of variceal bleeding in patients with previously untreated $\mathrm{EV}$ s ranges from $16 \%$ to $75.6 \%{ }^{[4,5]}$. In an earlier study examining the natural course of GVs, our group treated bleeding from GVs in 4 of 52 patients over a mean follow-up of 41 mo. Hemorrhage was successfully controlled in all 4 of these patients. Cumulative bleeding rates at 1,3 , and 5 years were $3.8 \%, 9.4 \%$, and $9.4 \%$, respectively ${ }^{[6]}$. The overall incidence of bleeding is thus higher for EVs than for GVs.

In another study, our group examined 70 cirrhotic patients with first episodes of bleeding from EVs or GVs; no patient had received prior treatment ${ }^{[7]}$. Red color signs were more common in EVs than in GVs. Mucosal 
erosions and ulcers at bleeding varices were more common in GVs than in EVs. Gastric erosions and ulcers were also more common in GVs than in EVs. Red color signs were frequently encountered in EVs, but were not found in fundal varices. All cardiac varices showing red color signs communicated with EVs, which also showed red color signs. The lack of red color signs in fundal varices might have been caused by the thick overlying mucosa. Gastric ulcers that develop on GVs invade the protective layer of the gastric mucosa. Invasion of the mucosal barrier overlying GVs increases the risk of massive bleeding, especially when fundal varices are involved. Such invasions might be an important precondition for variceal hemorrhage.

Endoscopic risk factors for bleeding from EVs include the presence of raised red markings, cherry-red spots, blue coloration, and large size $\mathrm{e}^{[8]}$. The North Italian Endoscopic Club for the Study and Treatment of Esophageal Varices ${ }^{[9]}$ reported that red color signs on EVs are predictive of bleeding.

\section{TREATMETN OF ESOPHAGEAL VARICES}

Treatment modalities for EVs include surgery, interventional radiology, and endoscopic treatment.

\section{Surgery}

A number of surgical procedures have been developed to manage EVs. These can be broadly classified as shunting procedures and nonshunting procedures.

Shunting procedures: The goal of shunting is to reduce the incidence of variceal bleeding by lowering the pressure in the portal system with a portal-systemic shunt. A standard portocaval shunt effectively reduces the incidence of variceal bleeding; however, impaired metabolism of hepatic protein after the procedure frequently causes hepatic encephalopathy due to hyperammonemia ${ }^{[10-12]}$. In 1967, Warren developed the distal splenorenal shunt (DSRS) to preserve portal blood flow through the liver, while lowering variceal pressure ${ }^{[13]}$. This approach was developed in the hope of preventing bleeding as well as hyperammonemia. Despite these initial expectations, DSRS has been found to effectively prevent rebleeding, but not eliminate the risk of hyperammonemia. To solve this problem, our group designed a DSRS with splenopancreatic disconnection and gastric transection, modifications to prevent the loss of shunt selectivity. Our modified DSRS has been confirmed to reduce the incidence of postoperative hyperammonemia ${ }^{[14]}$.

Non-shunting procedures: As an alternative to shunting, Hassab ${ }^{[15]}$ and Sugiura ${ }^{[16]}$ developed methods for gastroesophageal decongestion and splenectomy for the treatment of varices. The Hassab operation devascularizes the distal esophagus and proximal stomach. Splenectomy, selective vagotomy, and pyloroplasty can be performed concomitantly with the procedure. Sugiura ${ }^{[16]}$ developed a procedure for esophageal transection in patients with EVs and GVs. While both the Hassab and Sugiura procedures solve the problem of hepatic encephalopathy, varices are likely to recur earlier than they do after DSRS ${ }^{[17]}$.

\section{Interventional radiology}

In the 1970s, interventional radiology (IVR) techniques were developed for the treatment of EVs. Transportal obliteration, left gastric artery embolization, and partial splenic artery embolization are the principal IVR techniques used to treat EVs. Before performing IVR, portal hemodynamics should be determined. Angiography can determine the hemodynamics of varices during embolization.

Transportal obliteration: Two methods have been used to obliterate the feeding veins of EVs: percutaneous transhepatic obliteration and trans-ileocolic vein obliteration. These methods are performed similarly. A catheter is inserted directly into the portal vein, and the portal circulation is visualized by portography. A balloon catheter is inserted selectively into the inflow site of the feeding veins of the varices. The balloon is inflated, and a test dose of contrast medium is injected to determine the optimal volume of sclerosant. Five percent ethanolamine oleate with iopamidol (EOI), $500 \mathrm{~mL} / \mathrm{L}$ glucose, or both are injected to obliterate the feeding vein(s). Steel coils are then used to complete obliteration $^{[18]}$. The procedure is highly effective, although the complete disappearance rate of EVs is not so high after transportal obliteration alone.

Partial splenic artery embolization: Partial splenic artery embolization (PSE) has been performed to treat hypersplenism, EVs, GVs, portal hypertensive gastropathy, pancreatic carcinoma, and portosystemic encephalopathy ${ }^{[18-29]}$.

The femoral artery approach is used for superselective catheterization of the splenic artery. The tip of a catheter is placed as distally as possible in either the hilus of the spleen or in an intrasplenic artery. Embolization is achieved by injecting 2-mm gelatin-sponge cubes suspended in a saline solution containing antibiotics ${ }^{[23,30]}$. Similar to transportal obliteration, complete disappearance of EVs is difficult to achieve by PSE alone. PSE is thus a supplemental treatment for EVs.

\section{Endoscopic treatment}

Two endoscopic techniques are used to treat EVs: endoscopic injection sclerotherapy (EIS) and endoscopic variceal ligation $(E V L)^{[31-37]}$. Whenever possible, endoscopic treatment was performed at 2 -wk intervals by three expert endoscopists, using a television endoscopy system with computer-stored endoscopic images. After premedication with an intramuscular injection of scopolamine butylbromide $(20 \mathrm{mg})$, atropine sulfate $(0.25 \mathrm{mg})$, pentazocine (15 mg), hydroxyzine (25 mg), and diazepam (5 $\mathrm{mg}$ ) were injected intravenously. A one-channel endoscope was then inserted. A flexible endoscopic sheath (Sumitomo Bakelite, Tokyo, Japan) was used to permit reinsertion of the endoscope and to prevent aspiration.

Endoscopic injection sclerotherapy: EIS can be accomplished by either intravariceal EIS or extravariceal EIS $^{[32-34,38]}$

(1) Intravariceal EIS. An anal-side balloon was inserted into the stomach, and a 22-gauge needle was inserted into the target EV 2 to $3 \mathrm{~cm}$ proximal to the gastroesophageal junction. The sclerosant $(50 \mathrm{~mL} / \mathrm{L}$ EOI) was infused into 
the EV, and flow was monitored by X-ray fluoroscopy to confirm filling of the feeder vessel or the pericardiac venous plexus. Suction was maintained at the puncture point while the needle was in the EV. The same procedure was repeated for other variceal columns in the lower esophagus. Additional injections could not be performed, and the injection site was compressed by inflating the analside balloon with air.

In the treatment of EVs, intravariceal EIS obliterates both interconnecting perforating veins and feeding veins of EVs. Nearby, however, some dilated winding cardiac veins transverse the submucosa and directly join the EVs. This allows most cardiac varices to be treated concomitantly with EVs when correcting the latter by intravariceal EIS. Intravariceal EIS is useful for obliterating feeding veins of recurrent EVs after operation ${ }^{[34]}$. However, EIS is associated with high incidences of local and systemic complications ${ }^{[39]}$.

(2) Extravariceal EIS. Extravariceal EIS was performed with $10 \mathrm{~mL} / \mathrm{L}$ polidocanol to treat remaining varices by paravariceal injection ${ }^{[40]}$. The end point of primary treatment was the failure to detect any residual varices between the ulcers created by extravariceal EIS during the first hospitalization. Extravariceal EIS achieves local eradication, but does not completely disrupt the interconnecting perforating and feeder vessels ${ }^{[41]}$.

Endoscopic variceal ligation: There are various EVL devices for the treatment of EVs. We use a pneumoactivated EVL device (Sumitomo Bakelite) to treat EVs. EVL is increasingly used because of its safety and simplicity and because no sclerosant is required. EVL achieves local eradication, but does not completely disrupt the interconnecting perforating and feeder vessels ${ }^{[4]]}$.

We have devised a new intensive EVL method to more consistently eradicate $\mathrm{EVs}^{[31]}$. In comparison, the average total number of rubber bands used per patient was 9.6 in the standard EVL group and 19.9 in the intensive EVL group. EVs were completely obliterated in all patients in the intensive EVL group, but not in all patients in the standard EVL group ${ }^{[31]}$. Nevertheless, early recurrences of EVs after EVL have been reported ${ }^{[32]}$.

\section{Combination of endoscopic treatment and interventional radiology}

Our group previously reported that endoscopic treatment combined with IVR techniques significantly reduced longterm rates of rebleeding and retreatment in patients with $\mathrm{EVs}^{[18,24,26,27]}$.

Combination of endoscopic variceal ligation and partial splenic artery embolization: Cumulative recurrence rates at 1 and 2 years were lower in the EVL + PSE group than in the intensive EVL group $(P=0.042)$, suggesting that EVL + PSE therapy is effective for the management of $\mathrm{EVs}^{[24]}$.

Endoscopic treatment versus endoscopic treatment combined with interventional radiology: Cumulative retreatment rates in patients with Child's class $\mathrm{C}$ disease were lower after endoscopic treatment + IVR than after endoscopic treatment alone $(P=0.025)$. A combination of endoscopic therapy and IVR is effective therapy for EVs, especially in patients with poor liver function ${ }^{[18]}$.

Combination of endoscopic injection sclerotherapy and endoscopic variceal ligation: Several investigators have examined the efficacy of EVL combined with EIS for the treatment of $\mathrm{EVs}^{[42-44]}$. Saeed et $a l^{[42]}$ and Laine et $a l^{[43]}$ compared a single session of treatment with EVL plus low-volume EIS with a single session of EVL alone and concluded that EVL alone is superior to combination therapy. EVL was performed first, followed by intravariceal EIS immediately proximal to the ligature. The main limitation of this method is that only half of the feeding vessels are treated because the sclerosants are injected into the EV proximal to the ligature; distal vessels therefore do not undergo sclerosis.

EVL followed by EIS intrinsically differs from EIS followed by EVL. Moreover, the combination of intravariceal EIS and EVL differs from that of extravariceal EIS and EVL. EVL and extravariceal EIS both eradicate varices locally, with no effect on interconnecting perforating or feeding vessels ${ }^{[41]}$. Takase et $a l^{[45]}$ concluded that feeder vessels must be obliterated to prevent recurrence.

Beginning in November 1994, we developed a new technique combining EVL with EIS, called endoscopic scleroligation (ESL). In this technique, intravariceal EIS is performed before ligation. The puncture needle was removed after sclerosant infusion, and EVL was done simultaneously, including the placement of bands at the injection site. The same procedure was repeated for other EVs around the lower esophagus. Additional sclerosants were not injected. Intensive EVL was performed for EVs in the lower to middle esophagus ${ }^{[32]}$.

Intravariceal endoscopic injection sclerotherapy followed by endoscopic variceal ligation (ESL) versus intensive endoscopic variceal ligation: Both methods were equally effective with respect to complete eradication of EVs. Among patients in whom complete eradication was achieved, cumulative recurrence rates at 1 and 3 years were lower in the ESL group than in the intensive EVL group $(P<0.01)$. ESL was thus superior to intensive EVL in preventing variceal recurrence ${ }^{[32]}$.

Intravariceal endoscopic injection sclerotherapy followed by endoscopic variceal ligation (ESL) versus EVL followed by extravariceal EIS: Cumulative recurrence rates at 1 and 3 years in the ESL group were much lower than those in the EVL + extravariceal EIS group $(P<0.0001)^{[33]}$. Because intravariceal EIS was performed before ligation in ESL, all interconnecting perforating veins and feeder vessels were obliterated. This study supports the conclusion that the incidence of variceal recurrence is lower after ESL than after EVL + extravariceal EIS, although both methods were equally effective initially in terms of completely eradicating EVs.

Endoscopic variceal ligation followed by extravariceal endoscopic injection sclerotherapy versus intensive endoscopic variceal ligation: Fewer treatment sessions were needed $(P<0.005)$, and more $\mathrm{O}$-rings were required $(P<0.0001)$ in the EVL group than in the EVL + extravariceal EIS group. Cumulative recurrence rates at 1 and 3 years were higher in the EVL group 
than in the EVL + extravariceal EIS group $(P<0.05)$. Endoscopic examination at first recurrence showed that varices were more severe in form $(P<0.001)$, but less frequently associated with red color signs $(P<0.0001)$ and intramucosal venous dilatation $(P<0.0001)$ in the EVL group than in the EVL + extravariceal EIS group. Fewer rehospitalizations were required for additional treatment $(P<0.0001)$, and more patients received only endoscopic treatment for recurrent varices $(P<0.05)$ in the EVL group than in the EVL + extravariceal EIS group. These findings indicate that multiple EVL sessions are an effective treatment strategy for $\mathrm{EVs}^{[38]}$.

\section{New methods for the management of EVs: EVL at 2-mo intervals}

EVL and extravariceal EIS are not always effective, and early recurrences have been reported ${ }^{[32]}$. Furthermore, most patients with endoscopically treated EVs require followup therapy for recurrent varices. Proper management of recurrent EVs can significantly improve patients' quality of life.

In our previous study, the number of EVL sessions during the first hospitalization was $2.5 \pm 0.5^{[38]}$. Most EVs were ligated and deprived of blood after the first session. The remaining EVs were ligated in the second and subsequent sessions of EVL. Our findings suggested that the first EVL session had the most important role in blocking blood flow and stimulating shunt formation. After EVL alone, 1.8 subsequent hospitalizations were required for additional treatment of recurrent varices ${ }^{[38]}$. We judged that multiple blockages (at least three) of blood flow to EVs effectively stimulated shunt formation. We therefore defined three sessions to be one course in subsequent studies. The second treatment session after recanalization of variceal blood flow had a greater impact on the stimulation of shunt formation than did prior treatment sessions. This finding suggested that a prolonged interval between EVL sessions may improve treatment outcomes for EVs. However, we found that the bleeding rate of incompletely eradicated EVs was high and that bleeding from completely eradicated EVs occurred after only $6 \mathrm{mo}^{[32]}$. We therefore based the following study on the premise that three treatment sessions performed at 2-mo intervals (i.e., the third session begins 4 mo after the first session) would effectively prevent bleeding from EVs. Endoscopic variceal ligation bi-weekly versus bimonthly: We conventionally performed EVL treatment once every 2 wk (bi-weekly). We compared the short- and long-term results of EVL performed in three sessions with a total of 16 O-rings at two different intervals, i.e., biweekly (conventional interval) versus bi-monthly. A total of 63 patients with EVs were randomly assigned to receive one of these EVL treatments. Outcomes were assessed by an experienced physician who was blinded to the patients' treatment assignments. The overall rates of variceal recurrence and additional treatment were both higher after EVL bi-weekly than after EVL bi-monthly $(P<0.001)$. We concluded that EVL once every 2 mo (bi-monthly) resulted in better outcomes than EVL once every 2 wk (bi-weekly) in patients with EVs. Treatment sessions separated by a longer interval had a higher rate of total eradication and lower rates of recurrence and additional treatment ${ }^{[36]}$.

\section{REFERENCES}

1 The Japan Society for Portal Hypertension. The general rules for study of portal hypertension. 2nd ed. Tokyo: Kanehara Co., 2004: 37-50

2 Arakawa M, Kage M. Haemorrhage in the upper digestive tract due to portal hypertension: clinicopathological examinations of the foci of haemorrhage. J Gastroenterol Hepatol 1989; 4 Suppl 1: 168-170

3 Ide K, Nagasaki Y, Tomimatsu H, Nakashima T, Arakawa M, Kojiro M. Pathomorphologic and angio-architectural studies of oesophagogastric varices. J Gastroenterol Hepatol 1989; 4 Suppl 1: 204-207

4 Paquet KJ, Kalk JF, Klein CP, Gad HA. Prophylactic sclerotherapy for esophageal varices in high-risk cirrhotic patients selected by endoscopic and hemodynamic criteria: a randomized, single-center controlled trial. Endoscopy 1994; 26: 734-740

5 Triger DR, Smart HL, Hosking SW, Johnson AG. Prophylactic sclerotherapy for esophageal varices: long-term results of a single-center trial. Hepatology 1991; 13: 117-123

6 Tajiri T, Onda M, Yoshida H, Mamada Y, Taniai N, Yamashita $\mathrm{K}$. The natural history of gastric varices. Hepatogastroenterology 2002; 49: 1180-1182

7 Yoshida H, Onda M, Tajiri T, Mamada Y, Taniai N Endoscopic findings of bleeding esophagogastric varices. Hepatogastroenterology 2002; 49: 1287-1289

8 Beppu K, Inokuchi K, Koyanagi N, Nakayama S, Sakata H, Kitano S, Kobayashi M. Prediction of variceal hemorrhage by esophageal endoscopy. Gastrointest Endosc 1981; 27: 213-218

9 Prediction of the first variceal hemorrhage in patients with cirrhosis of the liver and esophageal varices. A prospective multicenter study. N Engl J Med 1988; 319: 983-989

10 Millikan WJ, Warren WD, Henderson JM, Smith RB, Salam AA, Galambos JT, Kutner MH, Keen JH. The Emory prospective randomized trial: selective versus nonselective shunt to control variceal bleeding. Ten year follow-up. Ann Surg 1985; 201: 712-722

11 Rikkers LF, Jin G. Variceal hemorrhage: surgical therapy. Gastroenterol Clin North Am 1993; 22: 821-842

12 Rikkers LF, Sorrell WT, Jin G. Which portosystemic shunt is best? Gastroenterol Clin North Am 1992; 21: 179-196

13 Warren WD, Zeppa R, Fomon JJ. Selective trans-splenic decompression of gastroesophageal varices by distal splenorenal shunt. Ann Surg 1967; 166: 437-455

14 Tajiri T, Onda M, Yoshida H, Mamada Y, Taniai N, Umehara M, Toba M, Yamashita K. Long-term results of modified distal splenorenal shunts for the treatment of esophageal varices. Hepatogastroenterology 2000; 47: 720-723

15 Hassab MA. Gastroesophageal decongestion and splenectomy in the treatment of esophageal varices in bilharzial cirrhosis: further studies with a report on 355 operations. Surgery 1967; 61: 169-176

16 Sugiura M, Futagawa S. A new technique for treating esophageal varices. J Thorac Cardiovasc Surg 1973; 66: 677-685

17 Tajiri T, Onda M, Yoshida H, Mamada Y, Taniai N, Yamashita $\mathrm{K}$. Comparison of the long-term results of distal splenorenal shunt and esophageal transection for the treatment of esophageal varices. Hepatogastroenterology 2000; 47: 1619-1621

18 Taniai N, Onda M, Tajiri T, Yoshida H, Mamada Y. Combined endoscopic and radiologic intervention to treat esophageal varices. Hepatogastroenterology 2002; 49: 984-988

19 Shimizu T, Onda M, Tajiri T, Yoshida H, Mamada Y, Taniai N, Aramaki T, Kumazaki T. Bleeding portal-hypertensive gastropathy managed successfully by partial splenic embolization. Hepatogastroenterology 2002; 49: 947-949

20 Tajiri T, Onda M, Taniai N, Yoshida H, Mamada Y. A comparison of combination endoscopic therapy and 
interventional radiology with esophageal transection for the treatment of esophageal varices. Hepatogastroenterology 2002; 49: 1552-1554

21 Yoshida H, Onda M, Tajiri T, Akimaru K, Uchida E, Arima Y, Mamada Y, Taniai N, Yamamoto K, Kaneko M, Kumazaki T. New techniques: splenic artery embolization followed by intraarterial infusion chemotherapy for the treatment of pancreatic cancer. Hepatogastroenterology 1999; 46: 2024-2027

22 Yoshida H, Onda M, Tajiri T, Uchida E, Arima Y, Mamada Y, Yamamoto K, Kaneko M, Terada Y, Kumazaki T. Experience with intraarterial infusion of styrene maleic acid neocarzinostatin (SMANCS)-lipiodol in pancreatic cancer. Hepatogastroenterology 1999; 46: 2612-2615

23 Yoshida H, Mamada Y, Taniai N, Yamamoto K, Kaneko M, Kawano Y, Mizuguchi Y, Kumazaki T, Tajiri T. Long-term results of partial splenic artery embolization as supplemental treatment for portal-systemic encephalopathy. Am I Gastroenterol 2005; 100: 43-47

24 Taniai N, Onda M, Tajiri T, Toba M, Yoshida H. Endoscopic variceal ligation (EVL) combined with partial splenic embolization (PSE). Hepatogastroenterology 1999; 46: 2849-2853

25 Taniai N, Onda M, Tajiri T, Yoshida H, Mamada Y. Interventional radiology and endoscopic therapy for recurrent esophageal varices. Hepatogastroenterology 2001; 48: 133-136

26 Yoshioka M, Onda M, Tajiri T, Akimaru K, Yoshida $\mathrm{H}$, Mamada Y, Taniai N, Mineta S, Hirakata A, Kumazaki T. Control of isolated gastric varices by combination therapy using embolization and endoscopic scleroligation therapy. Hepatogastroenterology 2002; 49: 955-957

27 Taniai N, Yoshida H, Mamada Y, Tajiri T. The treatment of gastric fundal varices--endoscopic therapy versus interventional radiology. Hepatogastroenterology 2005; 52: 949-953

28 Takahashi T, Arima Y, Yokomuro S, Yoshida H, Mamada Y, Taniai N, Kawano Y, Mizuguchi Y, Shimizu T, Akimaru $\mathrm{K}$, Tajiri T. Splenic artery embolization before laparoscopic splenectomy in children. Surg Endosc 2005; 19: 1345-1348

29 Shimizu T, Tajiri T, Yoshida H, Yokomuro S, Mamada Y, Taniai N, Kawano Y, Takahashi T, Arima Y, Aramaki T, Kumazaki T. Hand-assisted laparoscopic hepatectomy after partial splenic embolization. Surg Endosc 2003; 17: 1676

30 Tajiri T, Onda M, Yoshida H, Mamada Y, Taniai N, Kumazaki $\mathrm{T}$. Long-term hematological and biochemical effects of partial splenic embolization in hepatic cirrhosis. Hepatogastroenterology 2002; 49: 1445-1448

31 Masumori K, Onda M, Tajiri T, Kim DY, Toba M, Umehara M, Yoshida H, Mamada Y, Nishikubo H, Taniai N, Kojima T, Matsuzaki S, Yamashita K. Modified endoscopic variceal ligation. Dig Endosc 1995; 7: 165-170

32 Umehara M, Onda M, Tajiri T, Toba M, Yoshida H, Yamashita K. Sclerotherapy plus ligation versus ligation for the treatment of esophageal varices: a prospective randomized study. Gastrointest Endosc 1999; 50: 7-12

33 Tajiri T, Onda M, Yoshida H, Mamada Y, Taniai N, Umehara
M, Toba M, Yamashita K. Endoscopic scleroligation is a superior new technique for preventing recurrence of esophageal varices. J Nippon Med Sch 2002; 69: 160-164

34 Yoshida H, Onda M, Tajiri T, Toba M, Umehara M, Mamada Y, Taniai N, Yamashita K. Endoscopic injection sclerotherapy for the treatment of recurrent esophageal varices after esophageal transection. Dig Endosc 2002; 14: 93-98

35 Yoshida H, Onda M, Tajiri T, Mamada Y, Taniai N, Mineta S, Yoshioka M, Hirakata A, Yamashita K. New techniques: combined endoscopic injection sclerotherapy and ligation for acute bleeding from gastric varices. Hepatogastroenterology 2002; 49: 932-934

36 Yoshida H, Mamada Y, Taniai N, Yamamoto K, Kawano Y, Mizuguchi $Y$, Shimizu T, Takahashi T, Tajiri T. A randomized control trial of bi-monthly versus bi-weekly endoscopic variceal ligation of esophageal varices. Am J Gastroenterol 2005; 100: 2005-2009

37 Sarin SK, Govil A, Jain AK, Guptan RC, Issar SK, Jain M, Murthy NS. Prospective randomized trial of endoscopic sclerotherapy versus variceal band ligation for esophageal varices: influence on gastropathy, gastric varices and variceal recurrence. J Hepatol 1997; 26: 826-832

38 Yoshida H, Tajiri T, Mamada Y, Taniai N, Hirakata A, Kawano Y, Mizuguchi Y, Shimizu T, Takahashi T. Comparison of characteristics of recurrent esophageal varices after endoscopic ligation versus endoscopic ligation plus sclerotherapy. Hepatogastroenterology 2004; 51: 457-461

39 Schuman BM, Beckman JW, Tedesco FJ, Griffin JW, Assad RT. Complications of endoscopic injection sclerotherapy: a review. Am J Gastroenterol 1987; 82: 823-830

40 Obara K, Sakamoto H, Kasukawa R. Prediction of the recurrence of esophageal varices based on portal vein pressure and oxygen tension in portal and peripheral blood. Gastroenterol Jpn 1991; 26: 707-711

41 Hou MC, Lin HC, Kuo BI, Chen CH, Lee FY, Lee SD Comparison of endoscopic variceal injection sclerotherapy and ligation for the treatment of esophageal variceal hemorrhage: a prospective randomized trial. Hepatology 1995; 21: 1517-1522

42 Saeed ZA, Stiegmann GV, Ramirez FC, Reveille RM, Goff JS, Hepps KS, Cole RA. Endoscopic variceal ligation is superior to combined ligation and sclerotherapy for esophageal varices: a multicenter prospective randomized trial. Hepatology 1997; 25: 71-74

43 Laine L, Stein C, Sharma V. Randomized comparison of ligation versus ligation plus sclerotherapy in patients with bleeding esophageal varices. Gastroenterology 1996; 110: 529-533

44 Lo GH, Lai KH, Cheng JS, Lin CK, Huang JS, Hsu PI, Huang HC, Chiang HT. The additive effect of sclerotherapy to patients receiving repeated endoscopic variceal ligation: a prospective, randomized trial. Hepatology 1998; 28: 391-395

45 Takase Y, Shibuya S, Chikamori F, Orii K, Iwasaki Y. Recurrence factors studied by percutaneous transhepatic portography before and after endoscopic sclerotherapy for esophageal varices. Hepatology 1990; 11: 348-352

S- Editor Zhu LH $\quad$ L- Editor Zhu LH $\quad$ E- Editor Ma WH 